midwife may be found in the Steward's accounts of the Shuttleworths, \&c., in the county of Lancaster" :- "Spente by Will'm Woode and Cooke, wiffe and twoe horses, when they wente for the midwiffe of Wigan, being a day and a night away, 4s. Spente by Richard Stones when he brought the Wigan wiffe home, and a night away, 22d.; to the midwiffe, 12d." Then again we find at page 19s:- "Given to the midwiffe which helped cowe that could not calve, $2 s .6 u$."

Smyth mentions a mid wife who was fetched in 1558 from Cheddar, in Somersetshire, to London to attend a lady in her confinement, and received at her departure $6 s .8 d . \dagger$

OUTUINE OF A

\section{CASE OF OBSTRUCTION OF THE BOWELS, AND THE TREATMENT.}

\section{Bx J. BATTESON, M.R.C.S., L.S.A.}

Mrs. J_ _ aged thirty-three, healthy and well nourished, suffered from habitual constipation. On December 1st, 1871, she had had no action of the bowels for five days. Before the passage of the last stool she experienced great pain. ordered sulphate of magnesia in one-drachm doses every three hours, and a powder of calomel and jalap at bedtime. No action. Castol oil was then given, but with no result. The abdomen was now distended, there was general tenderness but not great pain, except on pressure in the left iliac region. A dull, aching pain extended over the lower part of the abdomen. On percussion the abdomen was tympanitic along the course of the cæcum and colon. In the left iliac region a dull sound was produced. No marked anxiety of countenance; no vomiting, and only small quantities of pale urine were passed; pulse quick and small. On examination per rectum, the bowel was found empty, the uterus, which felt heavy, interfering somewhat with the examination. The osophagus-tube passed up the rectum about eight or ten inches, and then met with some obstruction, beyond which it would not go. Only from fifteen to twenty ounces of fluid would remain by injection. Calomel and opium were at first administered, but after the first day of this treatment the calomel was discontinued, and opium only, in one-grain doses every four hours, was given. Enemata were used frequently. Small quantities of milk allowed.

Dec. 7th.--Met Dr. Moxon in consultation. At his sug gestion the patient was kept hungry and thirsty, no food being given, and only small quantities of ice to moisten the mouth being allowed. Hydraulic pressure was tried, but failed. Opium was now given in quantities of one grain every three hours.

9th.-Met Drs. Moxon and Madge in consultation. Abdomen was now much distended; occasional spasmodic pains; slight vomiting of mucus, but no stercoraceous matter; more urine voided. It was decided to continue the same treatment. Bougies were used, but could not be made to pass the obstruction. On the evening of this day patient had a severe attack of syncope, so brandy was freely given; but after each dose vomiting occurred. There being great restlessness, fifteen minims of nepenthe were injected subcutaneously, and much relief obtained.

11th. - Patient much weaker; countenance anxious; vomiting of offensive, dark, chocolate-like fluid. I called upon Dr. Moxon and explained condition of the case. We decided to invite Mr. Bryant to perform Amussat's operation at once, if after again seeing my patient $I$ considered her able to bear it. On returning I found the patient in a condition so nearly approaching syncope that I deemed it advisable to postpone the operation. On visiting her in the evening I found the tendency to syncope passed away. Administered another injection, and again tried hydraulic pressure, but with no good result.

While thinking what could be done for the poor creature, it occurred to me that if the reports of prisoners secreting instruments in their rectums were correct, it might be possible to pass the hand into the bowel; so, after explaining the matter to the patient and her husband, and having obtained permission to do as I liked, I proceeded as follows :-
Having bared my left arm, well oiled my hand and wrist, and put my fingers in the form of a wedge, I gently passed my hand through the sphincter ani in to the rectum. I then rested a minute, for my hand was puinfully cramped; then passed my fingers up to the sigmoid Hlexure of the colon, where they met with a stricture. At first I could only get the tip of my middle finger in the ring; but by steady pressure and moving the finger about, I pushed it up as far as the first joint: I was then able to get the tip of the ring-finger through the opening. Having again dilated it, I passed the osophagus-tube along the palm of $m y$ hand and through the opening, and then it easily passed several inches up the bowel. My assistant then injected a pint or more of warm water; this was allowed to remain in about five minutes, and then I removed the tube and my hand, when instantly there was a great rush of fæeal matter and Huid of a most offensive odour. After further injecting the bowel, six pounds or more of the pent-up secretion were liberated. The patient felt much relief, and rallied for a time, but afterwards relapsed into the condition of syncope, and died about three hours after the operation.

On inspecting the body thirteen hours after death there was no emaciation, there being much subcutianeous fat. On opening the abdomen, about a pint of fluid was found in the peritoneal cavity, most of which had probably escaped from the bowel, which had been perforated by an ulcer at the seat of stricture at the lower part of the sigmoid flexure. The small intestines were much distended, the large ones empty, and both were much congested. The strictured piece of bowel I have preserved.

Bow-road, E., Jan. 1872.

\section{DARWINISM TESTED BY RECENT RESEARCHES IN LANGUAGE.}

\section{BY FREDERIC BATEMAN, M.D.}

Tre author began by remarking that no works in modern times have exercised so great an influence for good or evil as the "Origin of Species" and the "Descent of Man," and that no more suitable arena could be selected for discussing Darwinism than the Victoria Institute.

Although announcing himself as a decided opponent of Darwinism, the author stated his intention of treating the subject fairly, observing that he had no a priori objection to raise against it, and that he should not reject it from any fancied notion that its adoption was derogatory to our dignity, or inconsistent with man's position in the order of nature. He was even prepared to admit that the descent of man from an ape may not be inconsistent with natural religion, but that it was directly opposed to revealed religion, which tells us that God formed man of the dust of the ground, and breathed into his nostrils the breath of life, and man became a living soul.

After a brief review of the main features and general purport of the "Descent of Man," and having called atten. tion to Mr. Darwin's statement that the difference in mind between man and the higher animals is one of deyree only, and not of kind, the author stated that the object of his paper was to show that man does possess a distinctive attribute of which not a trace can be found in the ape or lower animals-an attribute of such a nature as to create an immeasurable gulf between the two. This attribute he asserted to be the faculty of articulate Janguage, which he maintained to be the difference of lind which $\mathrm{Mr}$. Darwin is in search of

After stating what he understands by language, the author proceeded to discuss the question as to whether language be the exclusive prerogative of man, and having shown there is no analogy between the pantomimic and other forms of expression peculiar to animals and the articulate speech of man, he asserted that language is our rubicon, and no brute will pass it.

He then entered fully into the question of the seat of speech; for as the remarkable similarity between the brain of man and that of the ape cannot be disputed, if the seat of human speech could be positively traced to any particular part of the brain, the Darwinian could say that, althnuyh 
the ape could not speak, he possessed the germ of that faculty, and that, in subsequent generations, by the process of evolution, the speech-centre would become more developed and the ape would speak. He showed that none of the various theories as to the seat of language will stand the test of an impartial scrutiny, and he mentioned instances where persons could talk when the presumed seat of speech was invaded by an enormous tumour, completel disorganised by disease, or destroyed by a pistol-shot. With these facts before him, he asked whether speech, like the soul, may not be an attribute the comprehension of which is beyond the limits of our finite minds?

Having disclaimed all preconceived hostility to Mr. Dar win, the author concluded by saying that, as the scalpel of the anatomist had failed to discover a locus habitandi for man's proud prerogative, articulate language, as science had failed to trace speech to a "material centre"- had failed thus to connect matter with mind, he submitted that speech was the barrier between man and animals, constituting a difference between them not of degree only but of kind that the Darwinian analogy between the brain of man and that of his reputed ancestor, the ape, lost all its force, whilst the common belief in the Mosaic account of the origin of man was strengthened.

\section{A CASE OF SEPARATION OF THE PATELLA FROM ITS LIGAMENT UNDER PECU- LIAR CIRCUMSTANCES.}

BY F. ARTHUR DAVY, M.D.,

STAFF ASSTSTANT-SDRGEON IN MEDICAL CHARGE OF INVALIDS PROCEEDING rO BOMBAY.

Prrvate W. B-, of the Royal Scots, had been under treatment for many months during the past year at the Convalescent Depôt Hospital, Nynee Tab, for disease of the left knee-joint. $\mathrm{He}$ was under my care for some time in 1870 for the same disease, which was, without any doubt, due to syphilis. The disease commenced in the summex of 1870 , at Jhansie, and on account of it the patient is now travelling down country towards Bombay, being on his way (invalided for secondary syphilis) to England. $\mathrm{He}$ has also had subacute inflammation of the other jointsankles, right elbow, and one wrist; but at the time $I$ write these joints are giving very little trouble.

After reaching camp on the evening of February $7 \mathrm{th}$, be had nine attacks of violent tonic spasm, affecting all the muscles; these lasted for variable periods, averaging three minutes. The nine attacks or fits occurred between 4 P.M. and 8 P.M., during which time the patient was unconscious. There was no resemblance to true epilepsy in these seizures; they were much more like the tonic spasm of tetanus. The convulsions, however, never produced opisthotonos, or emprosthotonos. He has had, I am told, previous attacks of the same kind. Next morning the knee-joint was very much inflamed and swollen, and the patient could scarcely bear it to be touched. Hot water cloths were applied, and on the 9 th the swelling had greatly subsided. It was now possible to ascertain the condition of the joint. The condyles of the femur were distinctly seen; there was a depression where the patella ought to have been; and two inches above the joint was the patella, drawn up by the rectus femoris muscle. There had been subacute inflammation of the joint for a long time; and the disease must have involved the ligamentum patellæ; so that it offered little resistance to the powerfully contracting rectus. This man was not subject to the attacks of muscular spasm above mentioned when I knew him in 1870. They also are not improbably of syphilitic origin.

Moradalad, Feb. 13th, 1872.

A Certajn M. Donac has recently laid before the French Academy of Sciences a project for liquefying dead bodies and transforming them into a syrup without colour or smell. According to his calculations a moderate-sized man could be got into six bottles. The size of each bottle is not stated, but the Paris Journal appears charmed with the idea, and exclaims, "What an opening for the exercise of filial piety !'

\section{dy thetrror}

\author{
H O S I TAL PRACTICE, \\ BRITISH AND FOREIGN.
}

Nulla aut em est alia pro certo noscendi via, nisi quamplurimas et morborum et dissectionum historias, tum aliorum, tum pionrias sollectas habere, inter se comparare-MorgagN De Sed. et Caus. Morb., lib.iv. Prowmium.

\section{THE EXTRAORDINARY CASE OF FEIGNED DISEASE :}

HEMIPLEGIA, TETANUS, ETC.

As we anticipated, our report of the case of feigned hemiplegia and tetanus, which appeared in our issue of the 17th of February, has had the effect of eliciting from some of our readers further details concerning this most extraordinary and talented impostor. We have received facts concerning his conduct in the London Hospital, the German Hospital at Dalston, Horsemonger-lane Gaol, the Royal Infirmary at Windsor, and also in private life.

Dr. Hughlings Jackson has supplied us with the following facts, which, although written from memory, yet be feels certain are as stated :-

"A robust, dark-haired man of middle age, who gave the name of Leake, and who said he was a medical man, was admitted into the London Hospital for 'hemiplegia' in the latter part of 1868 . He was about, as he said, to join a vessel outward bound as a surmeon, when he was seized with paralysis. The hemiplegia was evidently simulated. The right arm and leg were 'paralysed,' the face was drawn to the left, and the tongue on protrusion turned to the rigbt. So far good. But, oddly enough, the 'paralysed' limbs were full of power ; they were kept straight out, and so rigid was the arm that I failed to bend it with all $m y$ force; nor could this be mistaken for rigidity of a pathological character. The hand was clenched like an ordinary fist. There was no complaint of pain on flexing the arm. The face was drawn to the left, not because the right side of the face was paralysed, but by effort; and the left cheek quivered from the constant exercise in which its muscles were engaged; the cheek was drawn far too much to the left. The tongue, when protruded, was directed to the right to a most absurd extent. No one who saw him had any doubt that the man was shamming, and I believe the patient himself was aware of this. The last time I saw him, I said in a significant tone, ' I know very well what is the matter with you.' He replied, as I thought, in an amused tone, 'I'm quite sure you do, sir.' Very soon afterwards he went out, having made some ridiculous complaint about his diet. He intended going to Guy's, and of ten spoke of one of the officials of that hospital always calling him 'his friend Mr. - When he left, I am told, he anathematised someone very strongly for accusing him of imposture; but I cannot get to know in what state his 'paralrsis' was when he left."

On May 25th, 1869, he appeared at the German Hospital, Dalston, where he went through his usual performance of hemiplegia. On this occasion he was bled. This was followed by diffuse inflammation of the arm, for the relief of which many and deep incisions were required. He bore all the necessary treatment heroically. He was discovered to be an impostor (quoad hemiplegia) about a week after his admission; but the state of his arm necessitated his staying in hospital till the end of June, when he suddenly picked a quarrel with a nurse and decamped.

On July 11 th, 1870, we find him in

$$
\text { of Bridewell, gloomy mound," }
$$

for withholding part of the proceeds of a subscription that he had raised on behalf of a poor widow. A short time after admission he showed symptoms of tetanus, and was removed to the infirmary; and a week later, the day previous to the one on which he had to appear at the police court, he had a severe apoplectic attack, and remained unconscinus for some time. His condition delayed his appearance in court so long that the widow got tired, and withdrew the charge. Our friend recovered at once, and requested a cab to be sent for that he might go home. This, 